forming the entire front of the heart, and hypertrophied, its muscular wall measuring three-tenths of an inch in thicknes--precisely the same thickness as the wall of the left ventricle.

In attacks of this kind it is not always possible to demonstrate clinically the temporary dilatation of the right side of the heart, but often it is unmistakable, and the fact seems to throw a light on the causation of this paroxysual dyspnoea. It seems to indicate an acute failure of the right ventricle to overcome the high tension in the pulmonary circuit, and to be analogous to the angina which sometimes is the result of an acute failure of the left ventricle to overcome increased tension in the aorta. If the dilatation of the right heart does produce this peculiar dyspno:a, in what way is the effect brought about? There is no great degree of cyanosis, yet the respiratory centre is acting strongly, for the inspirations are both rapid and deep. The vomiting which not seldom accompanies such attacks, the relief afforded by atropine, and the fact that occasionally an attack appears to be brought on by fright seem to indicate that there is a neurotic element in their causation. But that does not consist in a spasm of the bronchioles, for during the paroxysm there is not the general wheezing of an attack of asthma. The phenomena appear to me to afford support to the hypothesis that there is a nervous reflex from the right ventricle to the respiratory centre, and that when the ventricle fails cxcitement of this reflex causes dyspnoa.

4. Cardiac dyspnoca in general. - What is the causation of ordinary cardiac dysproea? It is characterised by a sort of air-hunger, and cannot be accounted for simply by the phy sical changes in the lungs which may result from cardiac disease. It is often much more severe than such resulting changes would account for, and it may exist when no such changes can be demonstrated. The check to the pulmonary circulation no doubt causes a deficiency in the aeration of the blood, but not for a long time sufficient cyanosis to account for the dyspnoea. It is well recognised that in cases of unitral disease the effectiveness of compensation depends on the vigour of action of the right ventricle. When there is marked epigastric pulsation compensation may be effectual in mitral disease, and there may be no dyspnœa; but if the right ventricle fails dyspnoea is at once observed. Is this through non-aeration of blood? Is it not more probably through excitation of a normal reflex to the respiratory centre?

5. Dyspnoca of muscular exertion.-.-Is not this due to the arcival of venous blood in the right side of the heart more rapidly than the ventricle is competent to pass it on into the lungs? Hence the tension in the right ventricle rises, the muscular walls tend to dilate, and a stimulus probably ascends to the respiratory centre, whereby more rapid and deeper inspirations expand the pulmonary channels and so relieve the labouring ventricle. Is not the management of the breath, which is a main part of the training for athletic exercises, simply an education of the right ventricle?

As to the path of this hypothetical reflex, it may be suggested that its afferent part is through the superficial or the deep cardiac plexus into the vagus. Possibly an irritation of this reflex through pressure on these plexuses may be the explanation of the paroxysmal dyspncea observed in some cases of aortic aneurysm, which also, as I have seen, may sometimes be almost immediately arrested by subcutaneous injections of atropine.

It seems to me also probable that a stimulating reflex exists from the right ventricle to the vaso-motor centre, which manifests itself in the increased arterial tension observed in mitral stenosis and in emphysema, but which is masked in the dilatation of the right ventricle (resulting from mitral regurgitation) by the depressing influence on the vaso-motor centre exerted by the dilated left ventricle. Such a stimulating reflex from the right ventricle to the vasonotor centre would increase the tension in the coronary arteries and thus promote the nutrition, and therefore the strength of contraction, of the right ventricle, in the same way as was observed by Professors Roy and Adami after narrowing the aorta.

Weymouth-street, W.

Adelatde Hospital, Dublin. - The Hudson Scholarship, which consists of a gold medal and $£ 30$, has this year been conferred on Mr. G. W. Eustace, and the Hudson Prize, silver medal, and $£ 10$ on Mr. Bertram D'Olier. Mr. J. Cecil Edge obtained the medical prize and also the surgical prize.

\section{THE SEQUEL OF A PUBLISHED CASE OF HYSTERO-EPILEPSY.}

By ALEX. ROBERTSON, M.D.GLASG.,

PROFESSOR OF MEDICINE, ST. MUNGO'S COLLEGE, GLASGOW.

THE early history of this case was recorded by Dr. McCall Anderson in THE LANCET of July 12th, 1879. The form of hysteria under which the patient suffered was then attracting a great deal of attention, especially through the writings of M. Charcot, whose death, still recent, is so great a loss to medicine. The features of peculiar interest in the cases which he and other French physicians had described were the effects of metallo-therapy and magnetism on the anxsthetic element of the disease and the phenomena of transference from one side of the body to the other. It will be seen from the following abstract of Dr. Anderson's account of his case, which will be first submitted, that the symptoms and the results of treatment by these agents were just as striking as those mentioned by the continental observers.

A domestic servant eighteen years of age was admitted into the Glasgow Western Infirmary on Feb. 14th, 1879, suffering from "fits." There was nothing particular in her family or previous personal history. She had only menstruated once, and that was about a month before her admission into the infirmary. Her illness was of three years' standing and had followed an attack of typhus fever. At first the seizures had been of monthly, but latterly were almost of daily, occurrence. If at any time she was startled, her left leg and arm, especially the latter, became firmly contracted for a moment. There was complete left hemi-anæsthesia of taste, touch, temperature, and pain. The deep as well as the superficial parts were anæsthetic. Thus a needle could be thrust into the muscles without the patient feeling it; the needle punctures bled only slightly. The mucous membranes on the affected side were also insensitive. There was amblyopia and almost complete achromatopsia of the left eye. There was some, but not great, impairment of power on the same side. On deep pressure in the region of the left ovary that organ was found to be enlarged and hyperæsthetic. The convulsive seizures were of the ordinary hystero-epileptic type. Treatment by metallo-therapy and the application of magnets was fully tried. It was found that the nervous symptoms were influenced to a certain extent by the application of gold coins to the affected side of the brow ; there was restoration of tactile sensation and that of pain over a part of the brow, and partial recovery of the colour-sense. Elsewhere on the affected side the anæsthesia continued complete; but this was very speedily altered by the action of the magnet. As its effect in the ward of the infirmary was the same as that produced by it when the girl was brought before a largely attended meeting of the Medico-Chirurgical Society about a fortnight after her admission, I shall quote the result as demonstrated at that meeting in Dr. Anderson's own words: "1. The ordinary magnet with keeper on had no effect, though used for at least ten minutes. 2. A large electro-magnet was employed by my colleague, Professor McKendrick. So long as the current was not allowed to pass there was no result, but in three minutes after the current was turned on, without her being made aware of it, the sensation returned to the left side of the body, while the right became anæsthetic and analgesic, being the reverse of her state before the electro-magnet was used." The magnet was brought near the patient, but did not actually touch her skin. It is well to state that care was taken, both by the appointment of a special committee of supervision and by the blindfolding of the girl at the time the observations were made, to eliminate all possibility of dissimulation by the patient-indeed, it was clear to me and to all those to whom I spoke that the idea of deception could not be entertained. The report goes on to state that on March 19th " internal metallo-therapy was resorted tothat is, the internal administration of the metal which, applied externally, caused a transference of the phenomena. Lead being one of the metals in question in this case, the acetate of lead in doses of two grains was given in pills thrice daily." Six days afterwards sensation returned somewhat suddenly to the left side. The left ovarian tenderness was also less, but partial colour-blindness remained. This was her condition when she left the infirmary on April 5th, 1879. Her leaving was owing to a quarrel with one of the servants; 
it is particularly noted that she had been very troublesome during her residence. The subsequent career of this young roman was a very sad one. On Oct. 20th of the same rear that she was dismissed from the Western Infirmary she was certified to be insane and sent to the City Parrohial Asylum under my care. Soon after admission into that establishment she had a series of fits of a brsterv-epileptic type. However, there was no recurrence of the anresthesia, except to a slight extent on one occasion, when there was also partial loss of colour-sense. The outstanding features of her disorder were ungovernable temper and sarage, unprovoked, and highly dangerous attacks on fellow patients and attendants. These unpleasant characteristics, it may be here said, were prominent in her subsequent confinements in asylums. Her first residence lasted tor eighteen months. From the date of her dismissal until ber death, which occurred on April 28th, 1893, she was a certified lunatic on eight different occasions. The total duration of her residence in institutions for the insane during this period was nine years. The later detentions were more protracted than the earlier ones. Thus from July 1st, 1886 , till she died she was for only two years and two months a free agent. When last in the City Asylum she was under treatment for seventeen months. At the time of her admission she was in an advanced stage of pregnancy. She was then melancholic, but this was the only occasion on which her mental disorder assumed that form. Its aspect soon changed, and she had become maniacal before her child was born. The attack of mania was very acute and very prolonged ; indeed, though the excitement had subsided to a great extent, she was still excitable and somewhat incoherent when removed to Dumfries Asylum in January, 1892. She was sent there with the hope that a change might act favourably on her health of body as well as of mind, for her general condition was not good. In her new quarters her bodily health improved for a time, but she ultimately succumbed to pulmonary phthisis. She died insane. It is important to note that the convulsive seizures became gradually fewer and appear to have ceased in the year 1886, without treatment directed specially towards their removal. There was no indication of their recurrence during pregnancy or the puerperal state.

Now that the case is closed, and that a survey can be taken of it from beginning to end, what conclusions are suggested respecting its nature and associations? It is obvious that there was throughout its whole course an intimate relation between the hystero-epilepsy and mental unsoundness. Even at the outset, when she was in the Western Infirmary, it can scarcely be doubted that the violent temper she displayed and her quarrelsome disposition were but the initial indications of the disturbance of psychic function which ultimately culminated in an attack of acute general mania. It would almost seem that the epileptoid and mental disorders held to each other in some degree a vicarious relationship ; for during the years she was having convulsive fits at intervals. even though her violent conduct and ungovernable tenper warranted and required her temporary confinement in an asylum for the insane, her mind was otherwise ustally clear and vigorons; but after the fits ceased her attacks of insanity came at shorter intervals and were more severe, terminating, as mentioned, in generalised acute mania. There is further evidence of the substitutionary tendency of the disorder, at the early part of her illness, in the ready transference of the anæsthesia from une side of the boly to the other under the action of a magnet. It is worthy of remark-though somewhat of a digression - that this form of temporary anæsthesia is quitedifferentfrom that which in some cases accompanies the ephemeral palsy of the affected side in unilateral convulsions. The latter passes away in an hour or two, eren sooner than the loss of motor power. ${ }^{1}$ The mental condition of the patient illustrates well the wide difference between hysteria of the type from which she suffered and ordinary "nervousness" in the popular sense. Sle was an excellent singer and always a much appreciated performer at the asylum concerts. When at her liberty she was also in the babit of singing at the public concerts of the city, In view of the instability of her nervous system I was much impressed by her perfect coolness and self-posses-

Though I directed attention to this variety of anæsthesia in the Prteiden al lecture of the Glasgow Pathological and Clinical Society in licis (Glasgow Medical Journal, December, 1879), $I$ have not yet seen i' referred to by other observers. It has, however, some bearing on a futes"ion respecting which there is at present marked difference of winion-namely, the sensory endowment of the so-called motor conrulutions. sion when singing before large audiences. What is the underlying pathological condition of the peculiar nervouk phenomena in this and similar cases? The word "instability," just used, expresses, though somewhat vaguely, an idea of its character. It is probably akin to the condition that arises in the hypnotic state. Temporary abeyance of function in related parts of the encephalon existed in $m y$ patient when anæsthesia was established; and so it apparently is under the fiat of the hypnotiser. But its intimate patho$\operatorname{logy}$ is still hidden : the nature of the molecular change that is doubtless present is not known. M. Charcot properly insists on the essential difference between hystero-epilepsy and epilepsy, and he refers to the preservation of mentat power in the former as one of several distinguishing features. This is unquestionably true; the two conditions have only a superficial resemblance. But, while agreeing with his dictum that there is no weakening of the intellect in the sense of slowness of apprehension and general obscuration, such as is usual in epilepsy of several years' standing, when the fits are of frequent occurrence, it is equally clear, as already stated, that there is marked instability; in this respect the mind is enfeebled. Though there is no particular reference to that point in M. Charcot's lectures on hysteria, still a perusal of the record of his cases of hystero-epilepsy produces the impression that the patients were wayward and unsettled and that the distance between their usual mental state and complete insanity was not great.

In conclusion I may remark that it is unfortunate for this class of patients that the striking phenomena of their nervous disorders prove to be so attractive to medical and other observers. The knowledge they soon acquire that their cases are of exceptional interest tends to concentrate their attention on their peculiar troubles, thereby maintaining and sometimes even intensifying the morbid state of the nervous system or which their disorders depend.

Newton-terrace, Glasgow.

\section{ON THE REPORT OF THE LEPROSY COM- MISSION IN INDIA, 1890-91.}

\section{A CRITICISM.}

BY G. ARMAUER HANSEN, M.D. INSPECTOR-GENERAL OF LEPROSY IN NORWAY.

THE Commission has treated all the questions in connexior with leprosy with great ability and thoroughness, and were I to go through the whole report this review would grow too long, especially as, on several points, I differ from the Commissioners. I will therefore only give the conclusions of the Commissioners in their own words and make some remarks thereon.

1. "Leprosy is a disease sui generis; it is not a form of syphilis or tuberculosis, but has striking etiological analogies with the latter." This is perfectly true.

2. "Leprosy is not diffused by hereditary transmission, and for this reason and the established amount of sterility among lepers the disease has a natural tendency to die out." With the first part of these words I of course agree, but not with the deductions of the Commissioners; they very properls point out the difference between a congenital and a hereditary disease, but nevertheless they say "it is obviously" fatal to the conception of an hereditary transmission of a constitution acquired from the parent if it be established that such conditions never appear congenitally." In my opinion the congenital appearance of a disease is a proof of the disease being contagious and not hereditary. A congenital disease and a congenital formation or malformation are two very different things. The Commissioners, by statistical researches on the spread of leprosy in India, have come to the conclusion that heredity has nothing to do with its propagation, but to conclude from this that the disease has a natural tendency to die out seems to me rather rash. It would follow that every disease not recognised as hereditary ought to have the same tendency, whereas that of course depende on the cause of the disease.

3. "Though in a scientific classification of disease leprosy. must be regarded as contagious and inoculable, yet the extent to which it is propagated by these means is exceedingly smal"." To this conclusion the Commissioners are led by only finding eight cases $f(r$ which contagiousness might be s 2 